\title{
Rare-earths doped-nanoparticles prepared by pulsed laser ablation in liquids
}

\author{
Hongli Du ${ }^{\mathrm{a}, \mathrm{b}, * *}$, Victor Castaing ${ }^{\mathrm{a}}$, Dongcai Guo ${ }^{\mathrm{b}}$, Bruno Viana $^{\mathrm{a}, *}$ \\ a PSL Research University, CNRS, Institut de Recherche de Chimie Paris, Chimie ParisTech, Paris, France \\ ${ }^{\mathrm{b}}$ College of Chemistry and Chemical Engineering, Hunan University, Changsha, China
}

\section{A R T I C LE IN F O}

Keywords

Laser ablation

Nanoparticles

Persistent luminescence

Rare-earths

\begin{abstract}
A B S T R A C T
This feature article highlights the recent advances on the lanthanide-activated nanoparticles prepared by pulsed laser ablation in liquids (PLAL). In the past decade, rare-earths-activated nanoparticles have been recognized from various applications including lots of high-tech products, green technologies, bioimaging and medical utilization. To obtain inorganic nanoparticles with different morphologies and sizes, pulsed laser ablation in liquids is a green and versatile technique. In this paper, a survey of the nanoparticle's formation during the laser ablation in the liquids is first introduced. We focus on the control of the size and morphology through proper laser parameters, choice of the reaction solution and proper surfactants. In the last part of the paper, we successfully prepared persistent luminescent $\mathrm{SrAl}_{2} \mathrm{O}_{4}: \mathrm{Eu}^{2+}, \mathrm{Dy}^{3+}$ by laser ablation in liquids and their optical features are investigated.
\end{abstract}

\section{Introduction}

With abundant and unique energy level structures arising from $4 \mathrm{f}^{\mathrm{n}}$ inner shell configurations, rare-earths-activated inorganic materials can exhibit emission mainly via intra- $4 \mathrm{f}$ or $5 \mathrm{~d}-4 \mathrm{f}$ transitions. When $4 \mathrm{f}-4 \mathrm{f}$ transitions are concerned, the luminescence features of trivalent lanthanides $\left(\mathrm{RE}^{3+}\right)$ will present high photo stability, high luminescence quantum yield, narrow bandwidth, long-lived emission, large Stokes shifts, and have received high interest because of the increasing demand for photoluminescence related applications, including lighting, electronic display, anti-counterfeiting, biological labeling, imaging [1], theranostic [2] etc. Among them, persistent luminescence [3-5] is a special property of $\mathrm{RE}^{3+}$ or transition metal doped materials with significant interest. Based on the nanoengineering development, the preparation of nano-sized lanthanide-activated materials is an important challenge [6]. Wet chemical methods, including sol-gel procedure [7], combustion synthesis [8], hydro-(solvo-) thermal route [9], coprecipitation [10], microwave synthesis [11], template method [12], and thermal decomposition [13] are commonly used routes to obtain nano-sized materials. Most of these chemical techniques require organic solvents during the synthesis which may cause toxic residues, highly undesirable in view of applications and for green chemistry. Pulsed laser ablation in liquids (PLAL) has demonstrated to be an efficient and versatile technique to produce high-quality nanoparticles (NPs) of a wide range of materials [14]. PLAL technique possesses a number of advantages over traditional methods previously cites. First, laser ablation process is considered as "green chemistry" process. Second, the nano- materials with size dispersion below $100 \mathrm{~nm}$ can be produced in faster and cleaner ways, even if sometimes the compounds quantity is at a limited value. Third, as long as there is the related laser equipment, experimental set up is minimal, and chemical precursors are replaced by bulk materials obtained by solid state reaction, so PLAL could be considered as a low-cost method. Finally, PLAL can be used to construct some complex structure compounds or modify the surface of nanoparticles, such as, inorganic nanoparticles coated with organic molecules that can be obtained in one step, in-situ or ex-situ [15]. Due to such advantages, the research on nanoparticles elaboration using PLAL has been of some interest during the last ten years. Looking at the topic literature, (see Fig. 1(a)), one can observed the increase interest for nanoparticles elaborated with PLAL technique and a large number of elements of the periodic table have been investigated as marked in Fig. 1 (b). As a summary in Fig. 1 (c), the nanoparticles obtained by PLAL methods with size ranged between 5 and $100 \mathrm{~nm}$ have been proposed in biological, optical devices or as photocatalyst.

Laser ablation technique could deliver large amounts of energy highly concentrated into one point of a material. Laser ablation of materials has been carried out in vacuum, in air and in liquids. Because of the unique confinement effect from liquid environment, there is many advantages when the laser ablation occurs in liquid. First, the work piece will be immersed into a liquid or be employed with a liquid film. The liquid environment could lower the heat load on the work piece, confines the vapor and plasma, and increases the shock pressure on the surface $[16,17]$. At the same time, the main fractions of the particles obtained by PLAL are often preserved with the same chemical composi-

\footnotetext{
* Corresponding author.

** Corresponding author. PSL Research University, CNRS, Institut de Recherche de Chimie Paris, Chimie ParisTech, Paris, France.

E-mail addresses: hongli.du@chimieparistech.psl.eu (H. Du); bruno.viana@chimieparistech.psl.eu (B. Viana)
} 


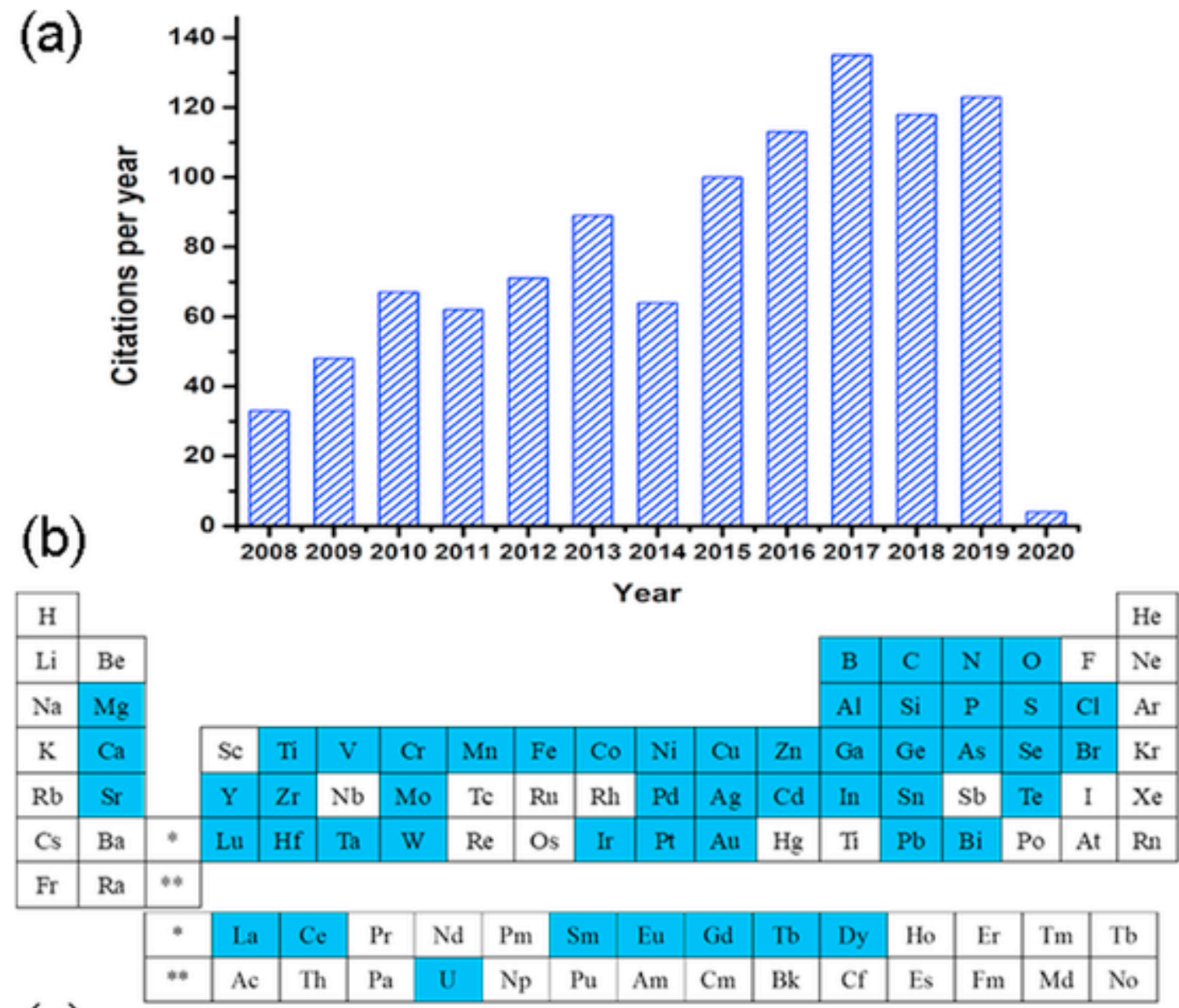

(c)

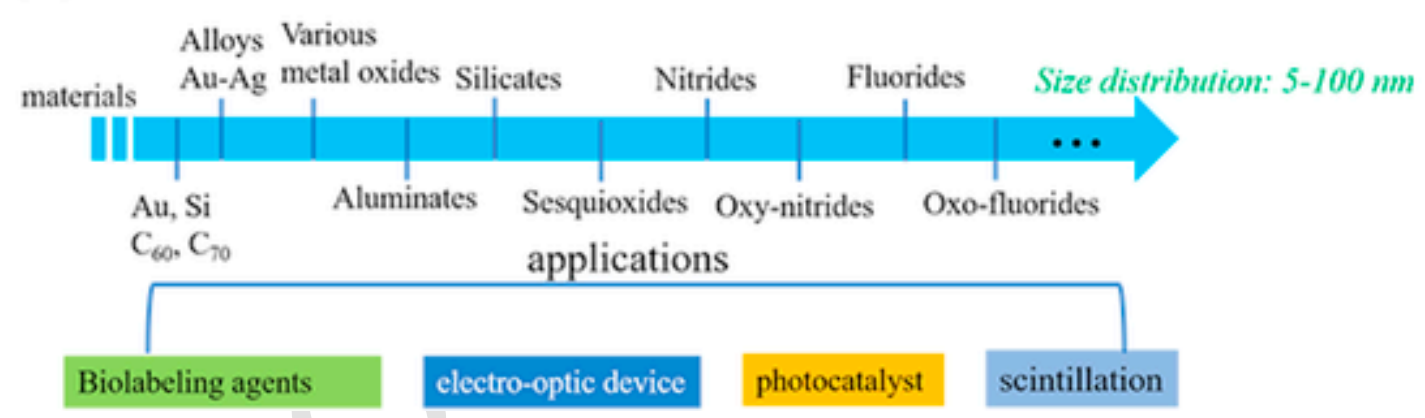

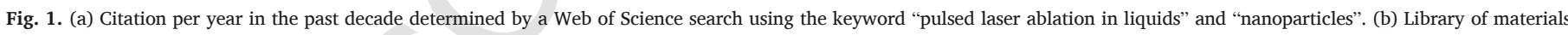
available for PLAL is summarized in the periodic table. (c) Materials synthesized through PLAL technique and applications.

tion as the bulk targets. This has been demonstrated with alloys [18], and various oxides-based compounds [19]. Therefore, PLAL is generally considered to combine top-down (micro-sized solid targets) and bottom-up (the formed plasma, atoms and clusters) methods with major processes controlled by laser plasma and physical cavitation [20]. However, as other chemical synthesis processes, several parameters have to be optimized to get the highest possible quality of materials. In case of PLAL techniques, laser parameters (such as wavelength, pulse duration, laser energy) and the liquid environment (solvent, temperature, surfactant for instance) are the key points to optimize.

The possible factors that could influence the formation of crystalline nanoparticles with controlled size and morphology are summarized in Fig. 2 [21]. In the following part, we will briefly report how these factors can control the nanoparticles formation.

\section{Nanoparticles formation mechanism under laser ablation}

During the whole laser ablation in liquids, the nanoparticles formation process can be described as follows: when the laser pulses irradiate the bulk target in liquids, breakdown process and plasma generation take place. Then, because of the liquid environment, a stronger confinement of the plasma and a fast energy transfer from the plasma to the surrounding liquid occur. Later, a cavitation bubble, which is a dynamic system with an expansion phase and a collapse phase, is formed. Finally, the cavitation bubbles collapse when the bubble reaches its maximum radius [20], and at the same time, NPs are released in the liquid to form a stable colloidal solution. So, the whole laser ablation process could also be considered as the plasma formation and cavitation bubbles action as well as the nanoparticles formation. The formed 


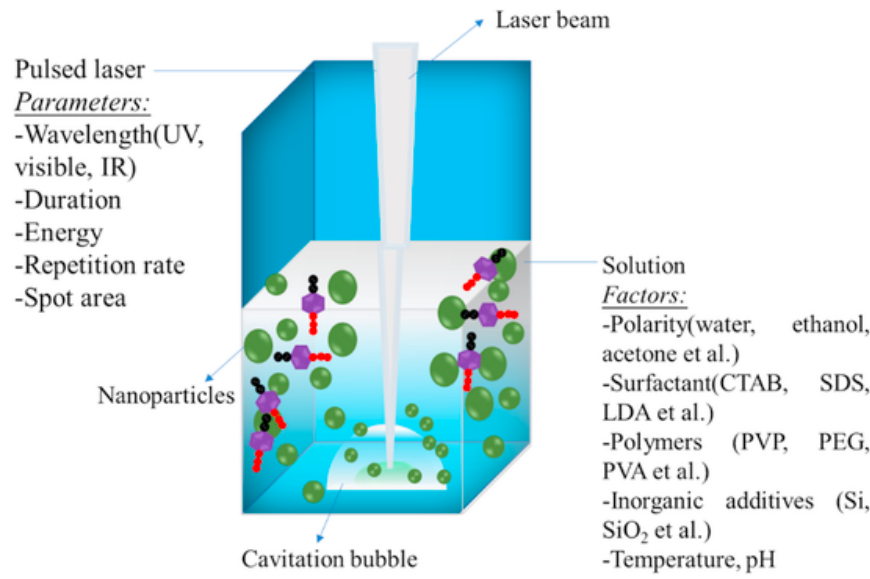

Fig. 2. Main factors affecting the nanoparticles formation by pulsed laser ablation in liquids media (adapted from Ref. [20]).

particles always present bimodal size distribution. The following part describes the main processes and bimodal size particles formation.

\subsection{Plasma formation, cavitation bubbles and nanoparticles formation}

The main process with the laser-target-liquid system can be summarized as following, when the laser is switched on, the microscopic dynamic action on the surface of the bulk target could go through three stages: plasma formation, cavitation bubbles expansion, and bubbles collapse with particles release (see Fig. 3 (a), (b) and (c) respectively) [22].

When laser pulses interact with a target immersed in a liquid, a plasma composed of highly ionized or atomic species is formed immediately. The plasma's temperature and pressure can be as high as thousands of Kelvin and hundreds of Pascal. This high pressure, high temperature, and high density of the plasma could provide a favorable thermodynamic environment for the formation of some NPs which are difficult to obtain by conventional chemical methods. But as Park's group reported [23], the duration of the plasma is generally in the range of tens of ns to few $\mu$ s for each laser pulse. So, it is difficult to determine the chemical reactions in the plasma. During the plasma decay, the energy is transferred to the liquid, producing a layer of vapor with roughly the same volume as the plasma, comparable to shockwaves. Shockwaves favor the chemical reaction of the ionized species in the expanded cavitation bubbles. Gilmore model [24] describes the cavitation bubble dynamics occurring during PLAL. In contrast, during bubble expansion and compression, the temperature inside the cavitation bubbles is only few hundreds of Kelvin. Recently, simulation results were experimentally verified [20].

\subsection{Bimodal size particles formation}

The particles obtained by PLAL technique often present bimodal size distribution. It has been reported that there is primary and secondary formation of NPs during the laser ablation. Small nanoparticles formation is based on thermal vaporization mechanism and larger particles formation is attributed to explosive boiling mechanism [25,26]. Soliman et al. have investigated the bubble action to give insights on the possible processes of primary and secondary NPs formation [27]. They concluded that primary particles are uniformly dispersed from the target surface toward the top of the cavitation bubble, and that their mass varies according to the bubble's shape. The secondary particles are dominant particularly in the center of the cavitation bubble, and they cannot penetrate into the liquid before the bubble collapses. Larger particles are formed after the collapsed of the bubble. In addition, Bonse et al. come up with the pulse duration-related mechanisms, and they proposed that size distribution could have a relationship with the beam intensity distribution on the target surface [28].

\section{Control of size, morphology and yield of the process}

To prepare nanoparticles with good performances, one should take into consideration the size, the morphology and the productivity or namely the quantitative yield of the process. For most laser systems, multiple tunable parameters may influence the preparation of the nanoparticles. Herein, some laser parameters and the choice of the solution are considered.

\subsection{Laser parameters}

For the laser experimental set up, there are many parameters that should be taken into account, the uppermost being the following: laser fluence, pulse duration, repetition rate, and laser wavelengths. Yield and size of nanoparticles (NPs) vary with main laser parameters summarize in Table 1. Among these laser parameters, each parameter could affect the others. For example, larger NPs could be formed with high-energy laser pulses [29], because high-energy laser pulses cause higher NPs formation yield and performed strong explosive boiling. This enhances aggregation and coalescence of the particles. On the contrary, it has been reported that reducing laser energy [30,31] could decrease both size and size-distribution of PLAL-synthesized particles. However, smaller NPs can be obtained with low energy laser pulses but unfortunately with lower yield [32]. In contrast, when laser pulse fluence increases, smaller sizes NPs can be generated with narrow size distribution [33]. Also, as Hamad et al. reported, when increasing the laser pulse duration, $\mathrm{TiO}_{2}$ NPs synthesized by PLAL in deionized water could lead to smaller particles [34]. Furthermore, considerations on the repetition rate, types of laser pulses, absorption by particles with fs, ps

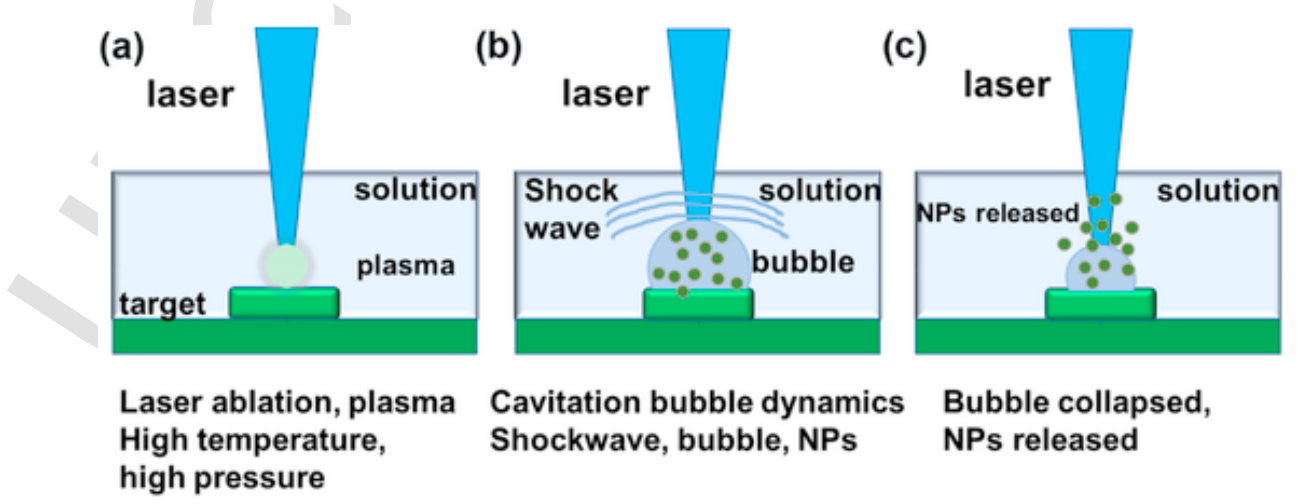

Fig. 3. Main processes of laser ablation occurring in solution (figure adapted from Ref. [22]). 
Table 1

Yield and size of nanoparticles (NPs) vary with main laser parameters (" $\downarrow$ " means increase and decrease, respectively).

\begin{tabular}{lllll}
\hline $\begin{array}{l}\text { Main laser } \\
\text { parameters }\end{array}$ & variation & yield & Size & Size distribution \\
\hline laser fluence [37] & $\uparrow$ & $\uparrow$ & $\uparrow$ & smaller NPs $\downarrow$; larger NPs $\uparrow$ \\
pulse duration [36] & $\uparrow$ & $\uparrow$ & $\downarrow$ & $\mathrm{ns}, \downarrow$; fs and ps, $\uparrow$ \\
repetition rate [38] & $\uparrow$ & $\uparrow$ & $\downarrow$ & $\uparrow$ \\
Wavelength [39] & $\mathrm{UV} \rightarrow \mathrm{NIR}$ & $\uparrow$ & $\uparrow$ & $\uparrow$ \\
\hline
\end{tabular}

and ns laser systems have been reported. Tsuji et al. defined: (i) "inter-pulse" energy absorption by the ablated particles with fast repetition rates and ultrafast lasers. (ii) "intra-pulse" absorption for ns laser systems. Another important laser parameter is the laser wavelength. It is reported that, under the same pulse duration, shorter-wavelengths (such as, 532 or $355 \mathrm{~nm}$ ) are a good choice to generate smaller size NPs $[35,36]$.

Taking all the laser parameters into consideration, it can be concluded that, the complexes and mutual cross-effects of laser parameters make difficult to develop a versatile system to control the size, and yield of the obtained nanoparticles. Then, one should take care of all these parameters based on the properties of the materials to get high-quality nanoparticles by PLAL technique.

\subsection{PLAL solutions}

For PLAL technique, the liquid or solution plays a very important role on the formation of nanoparticles. Solution is not only considered as a liquid medium to suspend the source particles but also strongly affects the size and stability of the obtained NPs as well as the production yield. In addition, possible chemical reactions such as oxidation or reduction [40] could occur. Then, solution with or without additives could have a large effect on the NPs size distribution and properties.

It has been reported that the nanoparticles can be prepared in various solutions. Maneeratanasarn et al. reported the synthesis of $\gamma-\mathrm{Fe}_{2} \mathrm{O}_{3}$ in ethanol and acetone liquid-phase by pulsed laser ablation technique, while amorphous $\alpha-\mathrm{Fe}_{2} \mathrm{O}_{3}$ was formed in deionized water [41]. Gökce et al. investigated plasmonic nanoparticles (copper, silver and gold) prepared in different solvents (water, acetone, ethanol and ethyl acetate). They found that the polarity of the solvents have a significant impact on the size, quantitative yield and growth dynamics of laser-generated nanoparticles, and concluded that smaller particles in a single growth regime can be obtained in more polar solvents [42].

The temperature of the solution could also have some influence on the property of obtained particles. With different temperatures, different sizes and morphologies of $\mathrm{ZnO}$ and $\mathrm{Zn}(\mathrm{OH})_{2}$ nanoparticles are formed [43]. ZnO columnar crystals were formed from $\mathrm{Zn}$ under laser pulses in deionized water at $80^{\circ} \mathrm{C}$. $\mathrm{ZnO}$ small nanoparticles are possibly produced by ablation even at a higher temperature than room temperature [44]. Haram et al. took silver and gold nanoparticles formation as example, and they found that increasing the temperature of the distilled water promoted the fusion of nanoparticles leading to the formation of nano-chains, nano-networks and super clusters [45].

In practice, the formed particles in solution are always charged. The ablated species formed during the laser ablation process have charged interfaces and different $\mathrm{pH}$ media result in nanoparticles with various degrees of aggregation. Palazzo et al. reported the stability of gold nanoparticles prepared by laser ablation in different $\mathrm{pH}$ media and concluded that a strong negative zeta-potential assures the stability against aggregation [46].

Some others parameters such as liquid depth above the target could also play significant role in the laser ablation process and therefore in the size of nanoparticles. Mahdied et al. investigated this parameter with nanosecond laser ablation in various water depths and concluded that optimized water depth above the target can result in the production of smaller size and uniform nanoparticles with narrow size distributions [47]. The dynamics of nanosecond pulsed laser ablation in liquids (ns-PLAL) could be significantly altered in the immediate vicinity of a free boundary. When the liquid layer thickness approximates the plasma size that is induced in bulk-liquid ablation, part of the plasma plume is formed outside the liquid [48]. The authors concluded that the liquid layer should be thicker than the plasma plume size to ensure laser-induced stresses which are useful for formation of the particles [48].

Furthermore, in order to improve the properties of nanoparticles obtained by PLAL, different kinds of additives, such as surfactants, salts, polymers, biomolecules, and organic solvents, can be applied to tune the NPs' size and modify the NPs' property. For instance, Abdi et al. used $\mathrm{CTAB}$ as cation surfactant to improve the degree of crystallinity of $\mathrm{ZnO}$ nanoparticles [49]. SDS as anion surfactant has often been used to control the size of the particles prepared with laser ablation in water [50]. In addition, for biological applications, biopolymers [51,52], such as albumin, starch, gelatin and chitosan are used in the laser ablation technique because they have a salting-out effect on the formation of NPs, in addition to their excellent biocompatibility and biodegradability. Concerning the shape of NPs, Mafuné et al. successfully designed core-shell structure to control the Ni NPs size during their formation by PLAL in water [53]. Silver nanoparticles can be loaded on silica support (SBA-15). Because of the stable silica support, smaller and more homogeneously dispersed nanoparticles can be elaborated.

\section{Rare-earths doped-nanoparticles}

With the increasing need of nanoparticles to be used in semiconductor and bio-applications, more and more researches focus on the rare-earth doped nanoparticles. Rare-earths doped nanoparticles present good photostability and wide possible optical features including the well-known up-conversation, down-conversation and persistent luminescence processes [54]. To obtain desired NPs sizes and properties with green and effective technique, PLAL method is one of the most effective method but not extensively used up to now. For optical nanoparticles, Park et al. successfully prepared the well-known $\mathrm{Y}_{3} \mathrm{Al}_{5} \mathrm{O}_{12}: \mathrm{Ce}^{3+}$ nanoparticles by PLAL with spherical shape and size ranging from 5 to $25 \mathrm{~nm}$. The obtained colloidal YAG:Ce ${ }^{3+}$ nanocrystals present good luminescence properties and similar optical features than their bulk counterparts [55]. In a domain of wide expansion, up-conversion nanoparticles have been prepared by PLAL and present good crystallinity and optical properties (see Table 2). When the nanoparticles are prepared in liquid, special solutions or additives could protect the NPs from defects on the surface, improve the properties of nanoparticles and favor their good dispersion. Then, researchers used surfactant [56] or inorganic additives [57] to improve the crystallinity, morphology and to limit size dispersion. Some of the researches on the lanthanide-activated nanoparticles prepared by PLAL have been summarized in Table 2 .

\section{Focus on $\mathrm{SrAl}_{2} \mathrm{O}_{4}: \mathrm{Eu}^{2+}, \mathrm{Dy}^{3+} \mathrm{NPs}$ persistent phosphor and challenges}

For the abundant applications of lanthanide-activated nanoparticles in various fields, such as, lighting, display, energy and biomedicine, it is necessary to obtain nanoparticles with high crystal quality, good morphology and uniform nano-sizes. Among the wet chemical synthesis methods, PLAL is one of the best ways to prepare lanthanide-activated nanoparticles with high crystallinity and multi-element compositions. Lots of lanthanide-activated nanoparticles have been synthesized by PLAL, for instance, lanthanide-based down-conversation [64] and up-conversation nanoparticles $[61,66]$. Concerning the persistent phosphors, the number of works is very limited. Recently, with transition 
Table 2

Lanthanide-activated nanoparticles prepared by PLAL technique.

\begin{tabular}{|c|c|c|c|}
\hline Materials & Solution \& surfactant & Morphology & $\begin{array}{l}\text { Siz } \\
(\mathrm{nr}\end{array}$ \\
\hline \multicolumn{4}{|l|}{ Garnets } \\
\hline $\mathrm{Y}_{3} \mathrm{Al}_{5} \mathrm{O}_{12}: \mathrm{Ce}^{3+}[55]$ & Deionized water & spherical & 5-: \\
\hline $\begin{array}{l}\mathrm{Y}_{3} \mathrm{Al}_{5} \mathrm{O}_{12}: \mathrm{Ce}^{3+} \\
(\mathrm{YAG}: \mathrm{Ce})[31]\end{array}$ & $\begin{array}{l}\text { deionized water \& } \\
\text { 2-[2-(2-methoxyethoxy)ethoxy]acetic } \\
\text { acid (MEEAA) }\end{array}$ & nanorod & $1 . \mathrm{c}$ \\
\hline $\begin{array}{l}\mathrm{Y}_{3} \mathrm{Al}_{5} \mathrm{O}_{12}(\mathrm{YAG}: \mathrm{Ce}) \\
{[58]}\end{array}$ & deionized water & string-like & 9 \\
\hline \multicolumn{4}{|l|}{ Silicates } \\
\hline $\mathrm{Gd}_{2} \mathrm{SiO}_{5}: \mathrm{Ce}^{3+}$ & Deionized water & / & $5-$ \\
\hline $\begin{array}{l}\mathrm{Sr}_{2} \mathrm{MgSi}_{2} \mathrm{O}_{7}: \mathrm{Eu}^{2+} \\
\mathrm{Dy}^{3+}[57]\end{array}$ & deionized water $+\mathrm{SiO}_{2}$ & $\begin{array}{l}\text { elliptical } \\
\text { nanorod }\end{array}$ & / \\
\hline $\begin{array}{l}\mathrm{Ca}_{2} \mathrm{Si}_{5} \mathrm{~N}_{8}: \mathrm{Eu}^{2+} \\
\mathrm{Tm}^{3+}[59]\end{array}$ & Water $\& \mathrm{NaOH}$ and acetate & web-like & 3.5 \\
\hline $\begin{array}{l}\text { Ca- } \alpha-S i A l O N: \mathrm{Eu}^{2+} \\
{[60]}\end{array}$ & deionized water & aggregation & 90. \\
\hline \multicolumn{4}{|l|}{ Fluorides } \\
\hline $\mathrm{NaYF}_{4}: \mathrm{Yb}^{3+} / \mathrm{Er}^{3+}$ & deionized water/ & spherical & 10. \\
\hline$[14,61]$ & $\begin{array}{l}\text { 2-[2-(2-Methoxyethoxy)ethoxy]acetic } \\
\text { acid (MEEAA) }\end{array}$ & & 40 . \\
\hline $\begin{array}{l}\text { YOF: } \mathrm{Er}^{3+}, \mathrm{Yb}^{3+} \\
{[62]}\end{array}$ & deionized water & nanorod & 20 . \\
\hline $\mathrm{NaGdF}_{4}: \mathrm{Nd}^{3+}[63]$ & DMSO & $\begin{array}{l}\text { not } \\
\text { completely } \\
\text { spherical }\end{array}$ & 20. \\
\hline \multicolumn{4}{|l|}{ Other Oxides } \\
\hline $\begin{array}{l}\mathrm{Y}_{2} \mathrm{O}_{3}: \mathrm{Eu}^{3+} \\
\mathrm{Lu}_{2} \mathrm{O}_{2} \mathrm{~S}: \mathrm{Eu}^{3+} \\
\mathrm{Lu}_{3} \mathrm{TaO}_{7}: \mathrm{Gd}^{3+} / \mathrm{Tb}^{3+} \\
{[64]}\end{array}$ & Deionized water & / & $5-:$ \\
\hline $\mathrm{Tb}_{3} \mathrm{Al}_{5} \mathrm{O}_{12}: \mathrm{Ce}^{3+}[65]$ & $\begin{array}{l}\text { deionized water \& lauryl } \\
\text { dimethylaminoacetic acid betain } \\
\text { (LDA) }\end{array}$ & / & / \\
\hline $\mathrm{Y}_{2} \mathrm{O}_{3}: \mathrm{Eu}^{3+}$ & deionized water \& & nanorod & $1 . \mathrm{C}$ \\
\hline $\mathrm{Gd}_{2} \mathrm{O}_{3}: \mathrm{Eu}^{3+}$ & $\begin{array}{l}\text { 2-[2-(2-methoxyethoxy)ethoxy]acetic } \\
\text { acid (MEEAA) }\end{array}$ & & \\
\hline $\begin{array}{l}\mathrm{Y}_{2} \mathrm{O}_{3}: \mathrm{Er}^{3+}, \mathrm{Yb}^{3+} \\
{[66]}\end{array}$ & deionized water & / & $\begin{array}{l}\text { Te1 } \\
\text { hul }\end{array}$ \\
\hline $\begin{array}{l}\mathrm{CaMoO}_{4}: \mathrm{Tm}^{3+} / \mathrm{Yb}^{3+} \\
{[67]}\end{array}$ & ethanol & spherical & 15 \\
\hline $\mathrm{NaYF}_{4}: \mathrm{Yb}^{3+} / \mathrm{Er}^{3+}$ & deionized water/ & spherical & 10. \\
\hline$[14,61]$ & $\begin{array}{l}\text { 2-[2-(2-Methoxyethoxy)ethoxy]acetic } \\
\text { acid (MEEAA) }\end{array}$ & & \\
\hline $\begin{array}{l}\mathrm{YVO}_{4}: \mathrm{Eu}^{3+} \\
{[19,56,68]}\end{array}$ & $\begin{array}{l}\text { deionized water/sodium dodecyl } \\
\text { sulfate }\end{array}$ & Ovoid-like & 30 \\
\hline
\end{tabular}

metal cations, nano-sized deep red persistent luminescent materials $\left(\mathrm{ZnGa}_{2} \mathrm{O}_{4}: \mathrm{Cr}^{3+}\right)$ were successfully prepared by the pulsed laser ablation in liquids without any surfactant [69]. The nanoscale particles present excellent deep red long persistent luminescence that may be use in the future as new probe in the first biological window. Indeed, in our laboratory in Paris, we have demonstrated the strong interest for this matrix for bio-imaging applications by a pioneer work published in 2011 [70] followed by important breakthroughs in the field [71-78]. Based on the previous works, $\mathrm{Ca}_{2} \mathrm{Si}_{5} \mathrm{~N}_{8}: \mathrm{Eu}^{2+}, \mathrm{Tm}^{3+}$ is one pioneer nice example of the capability of PLAL technique to obtain RE doped NPs with persistent luminescence, and we further performed the first real-time in vivo imaging with $\mathrm{Ca}_{2} \mathrm{Si}_{5} \mathrm{~N}_{8}: \mathrm{Eu}^{2+}, \mathrm{Tm}^{3+} \mathrm{NPs}$ obtained with PLAL method [59]. PLAL elaborated $\mathrm{Sr}_{2} \mathrm{MgSi}_{2} \mathrm{O}_{7}: \mathrm{Eu}^{2+}$, Dy ${ }^{3+}$ nano-phosphors can also present interesting persistent luminescence properties [57]. Following these pioneering works, the preparation of rare-earth doped persistent phosphors such as $\mathrm{SrAl}_{2} \mathrm{O}_{4}: \mathrm{Eu}^{2+}, \mathrm{Dy}^{3+}$ is encouraged through pulsed laser ablation in liquids.
$\mathrm{SrAl}_{2} \mathrm{O}_{4}: \mathrm{Eu}^{2+}, \mathrm{Dy}^{3+}$ compound, which is the most developed persistent phosphor due to its outstanding long afterglow time and intensity, has never been prepared by this technique even if previous elaboration under laser are presented in the literature $[78,79]$. Laser synthesis techniques yield nanosized particles but the annealing at high temperature required for the reduction of europium results in the formation of larger micro-sized agglomerates. The persistent luminescence researches on this material began more than twenty years ago, with the discovery of $\mathrm{SrAl}_{2} \mathrm{O}_{4}$ doped with $\mathrm{Eu}^{2+}$, then through co-doping with trivalent dysprosium, the afterglow was enhanced and reached more than $10 \mathrm{~h}$ [80]. Up to now, it is widely used in various identification and warning signs on buildings or highways. Furthermore, its high brightness and long-lasting time make this material interesting for further applications in biomedicine, very recently, Terraschke et al. coated magnetic nanoparticles with $\mathrm{SrAl}_{2} \mathrm{O}_{4}: \mathrm{Eu}^{2+}, \mathrm{Dy}^{3+}$ to open the path to combination of imaging and in situ manipulation of relevant biomolecules [81]. However, the elaboration of NPs still remains a challenge [82], which propels to prepare nano-sized $\mathrm{SrAl}_{2} \mathrm{O}_{4}: \mathrm{Eu}^{2+}, \mathrm{Dy}^{3+}$ phosphor.

\section{1. $\mathrm{SrAl}_{2} \mathrm{O}_{4}: \mathrm{Eu}^{2+}, \mathrm{Dy}^{3+}$ preparation and characterization}

The preparation of the $\mathrm{SrAl}_{2} \mathrm{O}_{4}: \mathrm{Eu}^{2+}, \mathrm{Dy}^{3+}$ persistent phosphor was realized through pulsed laser ablation in liquids under the following conditions. The sintered pellets are used as targets for preparation of $\mathrm{SrAl}_{2} \mathrm{O}_{4}: \mathrm{Eu}^{2+}, \mathrm{Dy}^{3+}$ nanophosphor. The experimental process to prepare pellets is introduced in Supporting Information. During the ablation process, the pellets are immersed in $50 \mathrm{~mL}$ of solution in a quartz cell, and irradiated with $1064 \mathrm{~nm}$-ns pulsed Nd:YAG laser at $10 \mathrm{~Hz}$ (see Fig. 4).

Different solutions such as water, ethanol, and acetone, different laser wavelengths $(355 \mathrm{~nm}, 1064 \mathrm{~nm})$ and different laser powers $(10 \mathrm{~mJ}, 400 \mathrm{~mJ})$ were used for the material preparation. The experimental conditions are summarized in Supporting Information, Fig. S1. Firstly, with the laser ablation in water, it appears impossible to obtain the $\mathrm{SrAl}_{2} \mathrm{O}_{4}: \mathrm{Eu}^{2+}, \mathrm{Dy}^{3+} \mathrm{NPs}$ but mainly $\mathrm{SrCO}_{3}$ was formed [57] as seen by XRD presented in Supporting Information, Fig. S2. This is due to the reaction between the $\mathrm{Sr}^{2+}$ ion and $\mathrm{CO}_{2}$ dissolved in water. In order to remove the $\mathrm{CO}_{2}$ from the solution, one should keep the process under $\mathrm{Ar}$ gas bubbling all along the synthesis. In ethanol and acetone solutions, as shown in Fig. 5 presenting the XRD patterns, the obtained particles present $\mathrm{SrAl}_{2} \mathrm{O}_{4}$ phase. As already reported, $\mathrm{SrAl}_{2} \mathrm{O}_{4}$ has a tridymite structure constructed by corner sharing $\mathrm{AlO}_{4}$ tetrahedra tilted with respect to each other [83]. The occupation of $\mathrm{Al}^{3+}$ cations in the compound induced a charge deficiency that is compensated by $\mathrm{Sr}^{2+}$ cation incorporation in channels created within rings of corner shared $\mathrm{AlO}_{4}$ tetrahedra, in the so-called stuffed tridymite structure [84]. There are two possible positions for $\mathrm{Sr}^{2+}$ cations in this matrix.

When laser energy value is fixed at $10 \mathrm{~mJ}$, with the near-infrared wavelength $(1064 \mathrm{~nm})$, the yield of the obtained particles appears larger than that with the UV wavelength $(355 \mathrm{~nm})$. For the same wavelength (1064 nm), but with much higher energy (400 mJ), higher yield and larger particles are obtained. This can be explained by the pulsed laser ablation mechanism in the solution as presented before. During the pulsed laser ablation on the pellet, cavitation bubbles will be formed on the surface of the pellet continuously, and with laser power increase, the cavitation bubbles lifetime increases. As a result, this will enhance the quantity of particles formed during the laser pulse. At the same time, high laser power may cause mechanical stress, as the temperature and pressure inside the plasma plume are increased. This could further result in a collapse of the cavitation bubbles, which thereby intensify the collision frequency among particles, leading to coalescence and larger particles formation $[85,86]$. Considering large productivity and good crystalline phase, $\mathrm{SrAl}_{2} \mathrm{O}_{4}: \mathrm{Eu}^{2+}, \mathrm{Dy}^{3+} \mathrm{NPs}$ were 
(a)

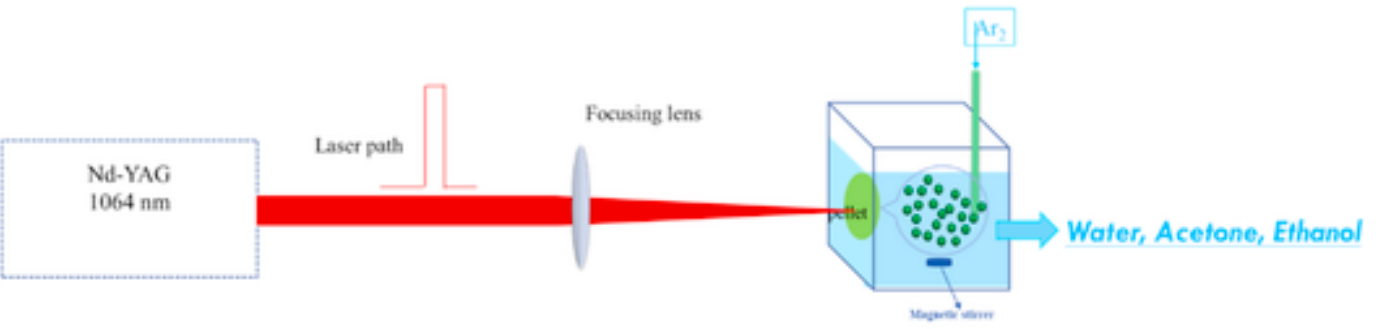

(b)

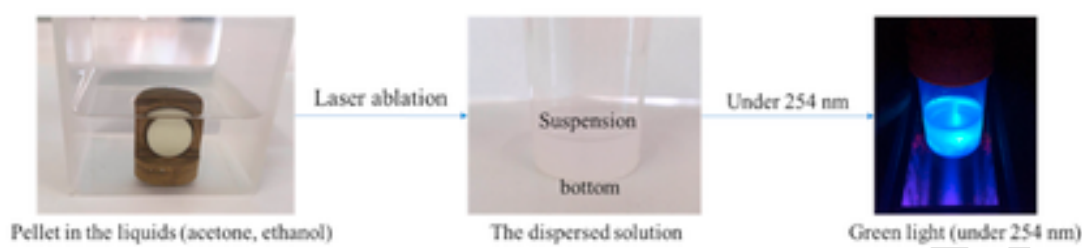

Fig. 4. (a) Schematic diagram of the PLAL experimental setup for $\mathrm{SrAl}_{2} \mathrm{O}_{4}$ : $\mathrm{Eu}^{2+}$, $\mathrm{Dy}^{3+}$ synthesis; (b) pictures of different states of the target pellet during the reaction process.

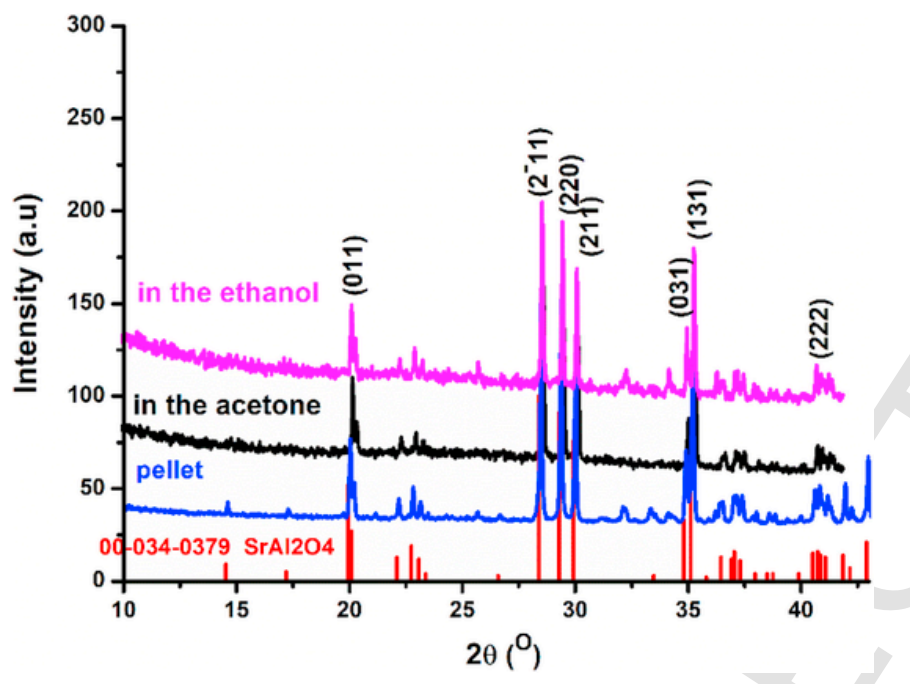

Fig. 5. XRD spectra of the synthesized particles in different solutions.

prepared in either ethanol or acetone with laser wavelength at $1064 \mathrm{~nm}$. Size distribution and optical feature are presented in the following part of the paper.

Fig. 6 shows images of the collected particles. The obtained particles present bimodal size distribution. Parts of the particles show micro-size (Fig. 6 (a)) while TEM image in Fig. 6 (b) presents nanoparticles with sizes around $7.5 \mathrm{~nm}$. As reported before, during the laser ablation process, particle size distributions could be composed of two modes. Small nanoparticles nucleate and grow in the target-solution mixing region based on thermal vaporization mechanism, while larger particles are formed by the fragmentation of the superheated molten

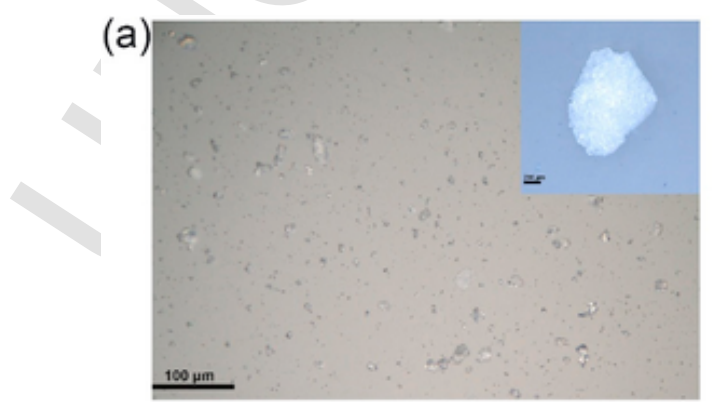

metal layer attributed to explosive boiling mechanism [26,87]. The size distributions of the thermal modes for each laser condition are very similar, only second fragmentation mode appears to vary with laser parameters. The micro size particles are formed like a "top-down" method, while nano size particles are formed by the thermal nucleation in the cavitation bubbles.

\subsection{Optical properties}

The photoluminescence spectra of the particles obtained by laser ablation in ethanol and acetone (laser wavelength $1064 \mathrm{~nm}$ ) are presented in Fig. 7.

The typical emission spectra of $\mathrm{SrAl}_{2} \mathrm{O}_{4}: \mathrm{Eu}^{2+}, \mathrm{Dy}^{3+}$ at $20 \mathrm{~K}$ with two emission bands located at $520 \mathrm{~nm}$ and $445 \mathrm{~nm}$ [88] are obtained for the laser ablation particles either in ethanol or acetone as shown in Fig. 7 (a). One could clearly observe an intensity variation between the two emission bands according to the elaboration medium. The two crystallographically different sites for $\mathrm{Sr}^{2+}$ have different coordination numbers, similar average $\mathrm{Sr}-\mathrm{O}$ distances (i.e., $2.886 \AA$ and $2.947 \AA$, respectively) [89], but slightly different individual $\mathrm{Sr}-\mathrm{O}$ distances. Indeed, the two environments differ by a slight distortion [90]. Considering the two slightly different $\mathrm{Sr}^{2+}$ sites, one can expect $\mathrm{Eu}^{2+}$ to occupy the sites more or less equally due to similar ionic radii. Non-radiative energy transfers occur at room temperature between these two sites as already reported in the same host [89] or in others hosts [91]. $\mathrm{Eu}^{2+}$ cations in Sr II sites should present broad emission band at higher energy $(445 \mathrm{~nm})$ while the $\mathrm{Eu}^{2+}$ in the Sr I sites should be responsible for the lower energy band $(520 \mathrm{~nm}$ ) (see insert Fig. 7). At higher temperature, the thermal energy promotes Sr II to Sr I energy transfer as shown the insert in Fig. 7(b), which leads to a strong decrease of the $445 \mathrm{~nm}$ emission band in favor to the $520 \mathrm{~nm}$ band. Thus, one observed redistribution of emission intensities from both sites at different tempera-

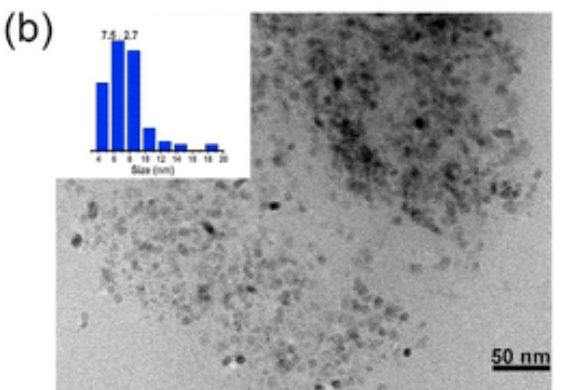

Fig. 6. Size distribution of the particles obtained in ethanol with $1064 \mathrm{~nm}$ : (a), micro-sized particles shown by Keyence VHX microscope; (b) nano-sized particles shown by TEM. 


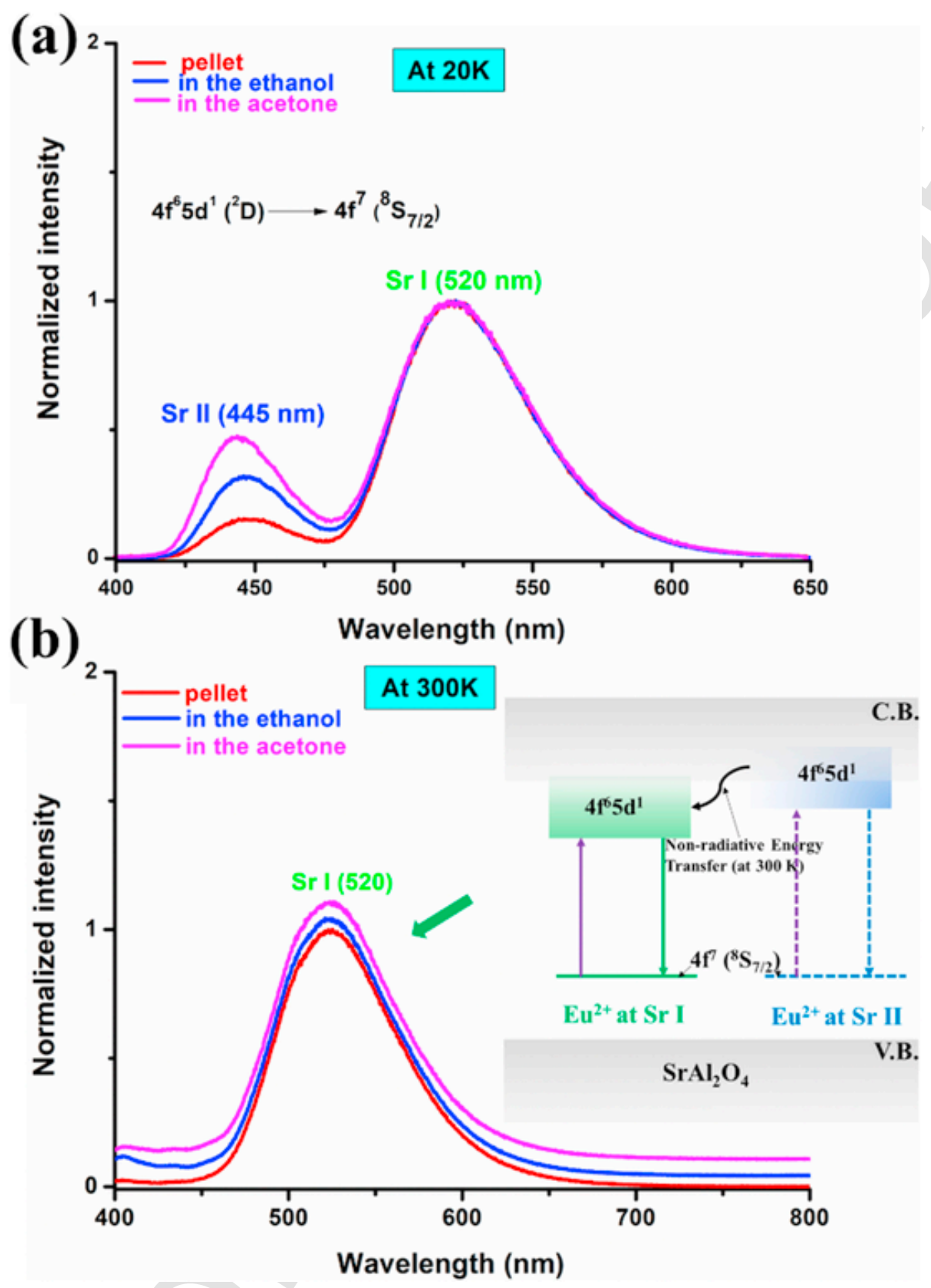

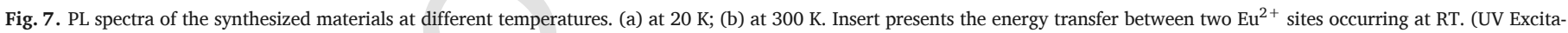
tion wavelength, $10 \mathrm{~Hz}$ ).

tures $[83,89,92,93]$. Furthermore, the intensity of the emission band at $445 \mathrm{~nm}$ from particles obtained in acetone is higher than that of pellet and particles obtained in ethanol, keeping the intensity at $520 \mathrm{~nm}$ constant, revealing different energy transfer efficiencies between the two sites according to the synthesis conditions. As Gökce et al. reported, through PLAL process, larger particles will be formed in ethanol in regard to acetone due to agglomeration occurring in less polar solvents [42]. Therefore, one can assume that the smaller particles obtained in acetone present larger energy transfer efficiency probably due to their crystal field variation around the $\mathrm{Eu}^{2+}$ ions [94,95].

$\mathrm{SrAl}_{2} \mathrm{O}_{4}: \mathrm{Eu}^{2+}, \mathrm{Dy}^{3+}$ bulk compounds present excellent long persistent luminescence. This phenomenon can be explained by the following processes: firstly, under UV light excitation, $\mathrm{Dy}^{3+}$ stabilized electrons trapping and enhanced the persistent luminescence; secondly, the electrons could be slowly released at room temperature and recombined with the excited state of $\mathrm{Eu}^{2+}$. Finally, when return to $\mathrm{Eu}^{2+}$ ground state, they give rise to persistent luminescence [80].

Fig. 8 shows the persistent luminescence decay profiles of the ablated $\mathrm{SrAl}_{2} \mathrm{O}_{4}: \mathrm{Eu}^{2+}, \mathrm{Dy}^{3+} \mathrm{NPs}$ in acetone and ethanol. After excitation at $365 \mathrm{~nm}$ for $5 \mathrm{~min}$ at room temperature, the particles present persistent luminescence, but much shorter than that of their bulk counterpart compounds. Indeed, after about $5 \mathrm{~min}$, the luminescence of the $\mathrm{SrAl}_{2} \mathrm{O}_{4}: \mathrm{Eu}^{2+}, \mathrm{Dy}^{3+} \mathrm{NPs}$ is too weak to be catched by eyes. The main possible reason is probably related to the ultra-small size of particles and surface effects that occur in the non-optimized process, but also may be due to a reduction of the effective trap density as already reported [96]. As can be seen in Fig. 8, the persistent luminescence of the particles obtained in acetone present slightly longer persistent decay than that in ethanol. As already known, persistent luminescence is controlled by the defects, which are not only associated with the parti- 


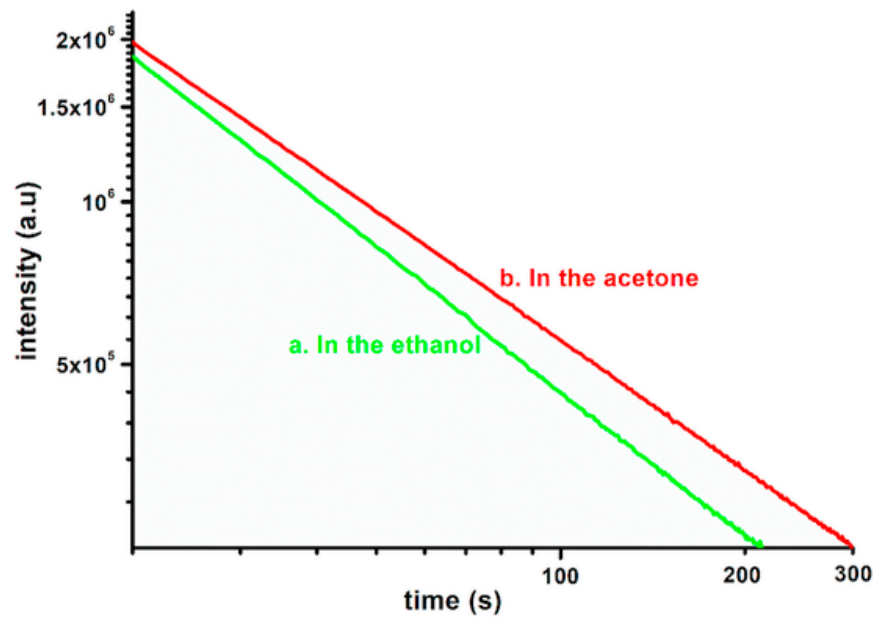

Fig. 8. Persistent decay curve of the ablated particles in acetone (a) and in ethanol (b) at $300 \mathrm{~K}$, after being excited at $365 \mathrm{~nm}$ for $5 \mathrm{~min}$.

cles size but also with the crystalline quality. Castaing et al. have demonstrated, in the $\mathrm{ZnGa}_{2} \mathrm{O}_{4}: \mathrm{Cr}^{3+}$ nano-glass ceramics, the strong effect of the crystalline quality on the persistent properties [97]. Cristoforetti et al. also reported that for particles prepared in acetone, enolate anions are formed on the particles surface and that ensures more stability [98]. Moreover, during the plasma creation, according to the solution, different reactive species can be formed. All that will have an influence on the defects and therefore on the persistent luminescence properties.

\section{Conclusions}

There is a lot of materials successfully prepared by PLAL. In order to elaborate nanoparticles with limited size, good morphology and outstanding properties through PLAL technique, various laser parameters, multiple solutions, and many others factors have been investigated. However, due to the complex inter-mutual-effects between these parameters, it is difficult to develop a standard in the experimental procedure, especially to manage the bimodal sized nanoparticles formation by PLAL, even if some experimental devices, such as filters, are known to help controlling the particles size. Furthermore, upscaling of the quantitative yield of nanoparticles is another important issue that still need to be solved.

In the present work, while difficult in aqueous medium we successfully synthesize $\mathrm{SrAl}_{2} \mathrm{O}_{4}: \mathrm{Eu}^{2+}, \mathrm{Dy}^{3+} \mathrm{NPs}$ with PLAL in acetone and ethanol solutions. At this time, control of uniform nano-size remains difficult while the intensity of the persistent luminescence is far from those obtained in the micro size compounds. In the following steps, one should further better control the laser parameters and use various additives in the solution to enhance the optical properties. In case of success, this should open the path to new applications and new modality for instance as bio-label or in catalysis applications.

\section{Declaration of competing interest}

The authors declare that they have no known competing financial interests or personal relationships that could have appeared to influence the work reported in this paper.

\section{Acknowledgments}

China Scholarship Council (CSC) Grant and ANR-18-CE08-0012 PERSIST for their support.

\section{Appendix A. Supplementary data}

Supplementary data to this article can be found online at https://doi. org/10.1016/j.ceramint.2020.04.291.

\section{References}

[1] H H Gorris, O S Wolfbeis, Photon-upconverting nanoparticles for optical encoding and multiplexing of cells, biomolecules, and microspheres, Angew. Chem. 52 (2013) 3584-3600.

[2] J H Liu, T Lecuyer, J Seguin, N Mignet, D Scherman, B Viana, C Richard, Imaging and therapeutic applications of persistent luminescence nanomaterials, Adv. Drug Deliv. Rev. 138 (2019) 193-210.

[3] A Abdukayum, J T Chen, Q Zhao, X P Yan, Functional near infrared-emitting $\mathrm{Cr}^{3+} / \mathrm{Pr}^{3+}$ co-doped zinc gallogermanate persistent luminescent nanoparticles with superlong afterglow for in vivo targeted bioimaging, J. Am. Chem. Soc. 135 (2013) 14125-14133.

[4] Y Zhuang, L Wang, Y Lv, T-L Zhou, R-J Xie, Optical data storage and multicolor emission readout on flexible films using deep-trap persistent luminescence materials, Adv. Funct. Mater. 28 (2018) 1705769.

[5] Y Li, M Gecevicius, J R Qiu, Long persistent phosphors-from fundamentals to applications, Chem. Soc. Rev. 45 (2016) 2090-2136.

[6] X Qin, X Liu, W Huang, M Bettinelli, X Liu, Lanthanide-activated phosphors based on $4 \mathrm{f}-5 \mathrm{~d}$ optical transitions: theoretical and experimental aspects, Chem. Rev. 117 (2017) 4488-4527.

[7] F Gao, H Liu, F Ren, K Wang, X Li, Y Wang, C He, Y Wei, Tunable structure and intensive upconversion photoluminescence for $\mathrm{Ho}^{3+}-\mathrm{Yb}^{3+}$ codoped bismuth titanate composite synthesized by sol-gel-combustion (SGC) method, Ceram. Int. (2019).

[8] H Chang, J Xie, B Zhao, B Liu, S Xu, N Ren, X Xie, L Huang, W Huang, Rare earth ion-doped upconversion nanocrystals: synthesis and surface modification, Nanomaterials 5 (2014) 1-25.

[9] C Wang, T Zhou, J Jiang, H Geng, Z Ning, X Lai, J Bi, D Gao, Multicolor tunable luminescence based on $\mathrm{Tb}^{3+} / \mathrm{Eu}^{3+}$ doping through a facile hydrothermal route, ACS Appl. Mater. Interfaces 9 (2017) 26184-26190.

[10] M N Luwang, R S Ningthoujam, S K Srivastava, R K Vatsa, Disappearance and recovery of luminescence in $\mathrm{Bi}^{3+}, \mathrm{Eu}^{3+}$ codoped $\mathrm{YPO}_{4}$ nanoparticles due to the presence of water molecules up to 800 degrees C, J. Am. Chem. Soc. 133 (2011) 2998-3004.

[11] M Yang, G Deng, T Hou, X Jia, Y Wang, Q Wang, B Li, J Liu, X Liu, Facile microwave-assisted synthesis of $\mathrm{Zn}_{2} \mathrm{GeO}_{4}: \mathrm{Mn}^{2+}, \mathrm{Yb}^{3+}$ uniform nanorods and near-infrared down-conversion properties, Opt. Mater. 64 (2017) 152-159.

[12] L S Lin, J Song, H H Yang, X Chen, Yolk-shell nanostructures: design, synthesis, and biomedical applications, Adv. Mater. (2018) 30.

[13] J C Boyer, F Vetrone, L A Cuccia, J A Capobianco, Synthesis of colloida upconverting NaYF4 nanocrystals doped with $\mathrm{Er}^{3+}, \mathrm{Yb}^{3+}$ and $\mathrm{Tm}^{3+}, \mathrm{Yb}^{3+}$ via thermal decomposition of lanthanide trifluoroacetate precursors, J. Am. Chem. Soc. 128 (2006) 7444-7445.

[14] W J Parak, M Osinski, X-J Liang, L Gemini, M-C Hernandez, R Kling, Formation of upconversion nanoparticles of $18 \% \mathrm{Yb}: 1 \% \mathrm{Er}: \mathrm{NAYF}_{4}$ by ultra-short pulse laser ablation in water, 2016, p. 9722972205

[15] J Lee, S Mahendra, P J Alvarez, Nanomaterials in the construction industry: a review of their applications and environmental health and safety considerations, ACS Nano 4 (2010) 3580-3590.

[16] H W Kang, H Lee, A J Welch, Laser ablation in a liquid-confined environment using a nanosecond laser pulse, J. Appl. Phys. 103 (2008) 083101.

[17] D J Hwang, T Y Choi, C P Grigoropoulos, Liquid-assisted femtosecond laser drilling of straight and three-dimensional microchannels in glass, Appl. Phys. A 79 (2004) 605-612.

[18] K Y Niu, J Yang, S A Kulinich, J Sun, X W Du, Hollow nanoparticles of metal oxides and sulfides: fast preparation via laser ablation in liquid, Langmuir: ACS J. Surf. Colloid. 26 (2010) 16652-16657.

[19] H Wang, O Odawara, H Wada, Facile and chemically pure preparation of YVO4:Eu ${ }^{3+}$ colloid with novel nanostructure via laser ablation in water, Sci. Rep. 6 (2016) 20507.

[20] M Dell'Aglio, R Gaudiuso, O De Pascale, A De Giacomo, Mechanisms and processes of pulsed laser ablation in liquids during nanoparticle production, Appl. Surf. Sci. 348 (2015) 4-9.

[21] V Amendola, M Meneghetti, What controls the composition and the structure of nanomaterials generated by laser ablation in liquid solution?, Phys. Chem. Chem. Phys. : Phys. Chem. Chem. Phys. 15 (2013) 3027-3046.

[22] S I Kudryashov, A A Samokhvalov, A A Nastulyavichus, I N Saraeva, V Y Mikhailovskii, A A Ionin, V P Veiko, Nanosecond-laser generation of nanoparticles in liquids: from ablation through bubble dynamics to nanoparticle yield, Materials 12 (2019) 15.

[23] K K Kim, M Roy, H Kwon, J K Song, S M Park, Laser ablation dynamics in liquid phase: the effects of magnetic field and electrolyte, J. Appl. Phys. 117 (2015) 074302

[24] F R Gilmore, The Growth or Collapse of a Spherical Bubble in a Viscous Compressible Liquid, 1952. 
[25] J P Sylvestre, A V Kabashin, E Sacher, M Meunier, Femtosecond laser ablation of gold in water: influence of the laser-produced plasma on the nanoparticle size distribution, Appl. Phys. A 80 (2005) 753-758.

[26] W T Nichols, T Sasaki, N Koshizaki, Laser ablation of a platinum target in water. II. Ablation rate and nanoparticle size distributions, J. Appl. Phys. 100 (2006) 114912.

[27] W Soliman, N Takada, K Sasaki, Growth processes of nanoparticles in liquid-phas laser ablation studied by laser-light scattering, Appl. Phys. Exp. 3 (2010) 035201.

[28] J Bonse, S Baudach, J Krüger, W Kautek, M Lenzner, Femtosecond laser ablation of silicon-modification thresholds and morphology, Appl. Phys. A 74 (2014) 19-25.

[29] M H Mahdieh, B Fattahi, Size properties of colloidal nanoparticles produced by nanosecond pulsed laser ablation and studying the effects of liquid medium and laser fluence, Appl. Surf. Sci. 329 (2015) 47-57.

[30] S B, A V K, F M W, M Meunier, Ultrafast laser based "green" synthesis of non-toxic nanoparticles in aqueous solutions, Appl. Phys. A 93 (2008).

[31] D Amans, C Malaterre, M Diouf, C Mancini, F Chaput, G Ledoux, G Breton, Y Guillin, C Dujardin, K Masenelli-Varlot, P Perriat, Synthesis of oxide nanoparticle by pulsed laser ablation in liquids containing a complexing molecule: impact on size distributions and prepared phases, J. Phys. Chem. C 115 (2011) 5131-5139.

[32] P Chewchinda, O Odawara, H Wada, The effect of energy density on yield of silicon nanoparticles prepared by pulsed laser ablation in liquid, Appl. Phys. A 117 (2014) 131-135.

[33] E Solati, L Dejam, D Dorranian, Effect of laser pulse energy and wavelength on the structure, morphology and optical properties of $\mathrm{ZnO}$ nanoparticles, Optic Laser. Technol. 58 (2014) 26-32.

[34] A Hamad, L Li, Z Liu, A comparison of the characteristics of nanosecond, picosecond and femtosecond lasers generated $\mathrm{Ag}, \mathrm{TiO}_{2}$ and $\mathrm{Au}$ nanoparticles in deionised water, Appl. Phys. Mater. Sci. Process 120 (2015) 1247-1260.

[35] T Tsuji, K Iryo, Y Nishimura, M Tsuji, Preparation of metal colloids by a laser ablation technique in solution: influence of laser wavelength on the ablation efficiency (II), J. Photochem. Photobiol. Chem. 145 (2001) 201-207.

[36] A Hamad, L Li, Z Liu, A comparison of the characteristics of nanosecond, picosecond and femtosecond lasers generated $\mathrm{Ag}, \mathrm{TiO}_{2}$ and $\mathrm{Au}$ nanoparticles in deionised water, Appl. Phys. A 120 (2015) 1247-1260.

[37] R A Ismail, A M Mousa, M H Amin, Effect of laser fluence on the structural, morphological and optical properties of $2 \mathrm{H}-\mathrm{PbI} 2$ nanoparticles prepared by laser ablation in ethanol, J. Inorg. Organomet. Polym. Mater. 28 (2018) 2365-2374.

[38] A Menéndez-Manjón, S Barcikowski, Hydrodynamic size distribution of gold nanoparticles controlled by repetition rate during pulsed laser ablation in water, Appl. Surf. Sci. 257 (2011) 4285-4290.

[39] K Zhang, D S Ivanov, R A Ganeev, G S Boltaev, P S Krishnendu, S C Singh, M E Garcia, I N Zavestovskaya, C Guo, Pulse duration and wavelength effects of laser ablation on the oxidation, hydrolysis, and aging of aluminum nanoparticles in water, Nanomaterials (2019) 9.

[40] T Tsuji, T Hamagami, T Kawamura, J Yamaki, M Tsuji, Laser ablation of cobalt and cobalt oxides in liquids: influence of solvent on composition of prepared nanoparticles, Appl. Surf. Sci. 243 (2005) 214-219.

[41] P Maneeratanasarn, T V Khai, S Y Kim, B G Choi, K B Shim, Synthesis of phase-controlled iron oxide nanoparticles by pulsed laser ablation in different liquid media, Phys. Status Solidi 210 (2013) 563-569.

[42] B Gökce, D D van't Zand, A Menéndez-Manjón, S Barcikowski, Ripening kinetics of laser-generated plasmonic nanoparticles in different solvents, Chem. Phys. Lett. 626 (2015) 96-101.

[43] G G Guillén, M I M Palma, B Krishnan, D Avellaneda, G A Castillo, T K D Roy, S Shaji, Structure and morphologies of $\mathrm{ZnO}$ nanoparticles synthesized by pulsed laser ablation in liquid: effects of temperature and energy fluence, Mater. Chem. Phys. 162 (2015) 561-570.

[44] Y Ishikawa, Y Shimizu, T Sasaki, N Koshizaki, Preparation of zinc oxide nanorods using pulsed laser ablation in water media at high temperature, J. Colloid Interface Sci. 300 (2006) 612-615.

[45] N Haram, N Ahmad, formation of gold and silver nanochains and nanonetworks by liquid assisted laser ablation at elevated temperature, J. Cluster Sci. 26 (2014) 713-725.

[46] G Palazzo, G Valenza, M Dell'Aglio, A De Giacomo, On the stability of gold nanoparticles synthesized by laser ablation in liquids, J. Colloid Interface Sci. 489 (2017) 47-56.

[47] M H Mahdieh, B Fattahi, Effects of water depth and laser pulse numbers on size properties of colloidal nanoparticles prepared by nanosecond pulsed laser ablation in liquid, Optic Laser. Technol. 75 (2015) 188-196.

[48] T T P Nguyen, R Tanabe-Yamagishi, Y Ito, Impact of liquid layer thickness on the dynamics of nano- to sub-microsecond phenomena of nanosecond pulsed laser ablation in liquid, Appl. Surf. Sci. 470 (2019) 250-258.

[49] S Abdi, D Dorranian, Effect of CTAB concentration on the properties of $\mathrm{ZnO}$ nanoparticles produced by laser ablation method in CTAB solution, Optic Laser. Technol. 108 (2018) 372-377.

[50] S I Alnassar, E Akman, B G Oztoprak, E Kacar, O Gundogdu, A Khaleel, A Demir, Study of the fragmentation phenomena of $\mathrm{TiO}_{2}$ nanoparticles produced by femtosecond laser ablation in aqueous media, Optic Laser. Technol. 51 (2013) 17-23.

[51] C Rehbock, V Merk, L Gamrad, R Streubel, S Barcikowski, Size control of laser-fabricated surfactant-free gold nanoparticles with highly diluted electrolytes and their subsequent bioconjugation, Phys. Chem. Chem. Phys.: Phys. Chem. Chem. Phys. 15 (2013) 3057-3067.
[52] M Barry, B Ding, Y Jung, B V K Reddy, T X Phuoc, M K Chyu, Pulsed nanosecond laser ablation of gold in deionized water and aqueous chitosan solution, Optic Laser. Eng. 55 (2014) 59-68.

[53] F Mafuné, T Okamoto, M Ito, Surfactant-free small Ni nanoparticles trapped on silica nanoparticles prepared by pulsed laser ablation in liquid, Chem. Phys. Lett. 591 (2014) 193-196.

[54] D Jaque, C Richard, B Viana, K Soga, X G Liu, J G Sole, Inorganic nanoparticles for optical bioimaging, Adv. Optic Photon 8 (2016) 1-103.

[55] G S Park, K M Kim, S W Mhin, J W Eun, K B Shim, J H Ryu, N Koshizaki, Simple route for $\mathrm{Y}_{3} \mathrm{Al}_{5} \mathrm{O}_{12}: \mathrm{Ce}^{3+}$ colloidal nanocrystal via laser ablation in deionized water and its luminescence, Electrochem. Solid State Lett. 11 (2008) J23.

[56] H Wang, O Odawara, H Wada, One-step preparation of $\mathrm{YVO}_{4}: \mathrm{Eu}^{3+}$ nanoparticles by pulsed laser ablation, J. Alloys Compd. 683 (2016) 1-6.

[57] M Ishizaki, T Katagiri, T Sasagawa, Y Kitamoto, O Odawara, H Wada, Preparation of $\mathrm{SiO}_{2}$-capped $\mathrm{Sr}_{2} \mathrm{MgSi}_{2} \mathrm{O}_{7}$ :Eu,Dy nanoparticles with laser ablation in liquid, $\mathrm{J}$. Nanotechnol. 2012 (2012) 1-6.

[58] N Tsuruoka, T Sasagawa, T Yodo, M Yoshimoto, O Odawara, H Wada, Facile preparation of YAG:Ce nanoparticles by laser irradiation in water and their optical properties, SpringerPlus 5 (2016) 325

[59] G S T Maldiney, B Viana, D Gourier, C Richard, D Scherman, M Bessodes, K Van den Eeckhout, D Poelman, P F Smet, In vivo optical imaging with rare earth doped $\mathrm{Ca}_{2} \mathrm{Si}_{5} \mathrm{~N}_{8}$ persistent luminescence nanoparticles, Opt. Mater. Express 2 (2012).

[60] H Wang, T Tomiya, T Takeda, N Hirosaki, O Odawara, H Wada, Fabrication of nanoscale $\mathrm{Ca}-\alpha-\mathrm{SiAlON}: \mathrm{Eu}^{2+}$ phosphor by laser ablation in water, Appl. Phys. Exp. 8 (2015) 115001

[61] L Gemini, T Schmitz, R Kling, S Barcikowski, B Gokce, Upconversion nanoparticles synthesized by ultrashort pulsed laser ablation in liquid: effect of the stabilizing environment, ChemPhysChem: Eur. J. Chem. Phys. Phys. Chem. 18 (2017) 1210-1216.

[62] R Anjana, K M Kurias, M K Jayaraj, Clean synthesis of YOF:Er ${ }^{3+}, \mathrm{Yb}^{3+}$ upconversion colloidal nanoparticles in water through liquid phase pulsed laser ablation for imaging applications, Opt. Mater. 72 (2017) 730-736.

[63] J Dai, G Feng, S Wang, H Zhang, S Dai, S Zhou, Transparent NaGdF 4 : $\mathrm{Nd}^{3+}$ colloid prepared by femtosecond laser ablation as a liquid laser medium, Optic Laser. Technol. 92 (2017) 202-205.

[64] G Ledoux, D Amans, C Dujardin, K Masenelli-Varlot, Facile and rapid synthesis of highly luminescent nanoparticles via pulsed laser ablation in liquid, Nanotechnology 20 (2009) 445605.

[65] S W Mhin, J H Ryu, K M Kim, G S Park, H W Ryu, K B Shim, T Sasaki, N Koshizaki, Pulsed-laser-induced simple synthetic route for $\mathrm{Tb}_{3} \mathrm{Al}_{5} \mathrm{O}_{12}$ :Ce colloidal nanocrystals and their luminescent properties, Nanoscale Res. Lett. 4 (2009) 888-895.

[66] T Ikehata, Y Onodera, T Nunokawa, T Hirano, S-i Ogura, T Kamachi, O Odawara, $\mathrm{H}$ Wada, Photodynamic therapy using upconversion nanoparticles prepared by laser ablation in liquid, Appl. Surf. Sci. 348 (2015) 54-59.

[67] K Cho, J Choi, J-I Lee, J H Ryu, Pulsed-laser-assisted synthesis of a $\mathrm{Tm}^{3+} / \mathrm{Yb}^{3}$ co-doped $\mathrm{CaMoO}_{4}$ colloidal nanocrystal and its upconversion luminescence, $\mathrm{J}$. Kor. Phys. Soc. 68 (2016) 22-27.

[68] $\mathrm{H}$ Wang, O Odawara, $\mathrm{H}$ Wada, Morphology and optical properties of $\mathrm{YVO}_{4}$ :Eu $3+$ nanoparticles fabricated by laser ablation in ethanol, Appl. Surf. Sci. 425 (2017) 689-695.

[69] M S Relvas, M R N Soares, S O Pereira, A V Girão, F M Costa, T Monteiro, Trends in $\mathrm{Cr}^{3+}$ red emissions from $\mathrm{ZnGa}_{2} \mathrm{O}_{4}$ nanostructures produced by pulsed laser ablation in a liquid medium, J. Phys. Chem. Solid. (2019)

[70] A Bessiere, S Jacquart, K Priolkar, A Lecointre, B Viana, D Gourier, $\mathrm{ZnGa}_{2} \mathrm{O}_{4}: \mathrm{Cr}^{3+}$ : a new red long-lasting phosphor with high brightness, Optic Express 19 (2011) 10131-10137.

[71] T Maldiney, A Bessiere, J Seguin, E Teston, S K Sharma, B Viana, A J Bos, P Dorenbos, M Bessodes, D Gourier, D Scherman, C Richard, The in vivo activation of persistent nanophosphors for optical imaging of vascularization, tumours and grafted cells, Nat. Mater. 13 (2014) 418-426.

[72] N Basavaraju, K R Priolkar, D Gourier, S K Sharma, A Bessiere, B Viana, The importance of inversion disorder in the visible light induced persistent luminescence in $\mathrm{Cr}^{3+}$ doped $\mathrm{AB}_{2} \mathrm{O}_{4}(\mathrm{~A}=\mathrm{Zn}$ or $\mathrm{Mg}$ and $\mathrm{B}=\mathrm{Ga}$ or $\mathrm{Al})$, Phys. Chem. Chem. Phys.: Phys. Chem. Chem. Phys. 17 (2015) 1790-1799.

[73] N Basavaraju, S Sharma, A Bessière, B Viana, D Gourier, K R Priolkar, Red persistent luminescence in $\mathrm{MgGa}_{2} \mathrm{O}_{4}: \mathrm{Cr}^{3+}$; a new phosphor for in vivo imaging, $\mathrm{J}$. Phys. Appl. Phys. 46 (2013) 375401

[74] T Lecuyer, E Teston, G Ramirez-Garcia, T Maldiney, B Viana, J Seguin, N Mignet, D Scherman, C Richard, Chemically engineered persistent luminescence nanoprobes for bioimaging, Theranostics 6 (2016) 2488-2524.

[75] B Viana, S K Sharma, D Gourier, T Maldiney, E Teston, D Scherman, C Richard, Long term in vivo imaging with $\mathrm{Cr}^{3+}$ doped spinel nanoparticles exhibiting persistent luminescence, J. Lumin. 170 (2016) 879-887.

[76] A Bessière, A Lecointre, R A Benhamou, E Suard, G Wallez, B Viana, How to induce red persistent luminescence in biocompatible $\mathrm{Ca}_{3}\left(\mathrm{PO}_{4}\right)_{2}$, J. Mater. Chem. C 1 (2013) 1252-1259.

[77] $\mathrm{J} \mathrm{Xu}$, J Ueda, Y Zhuang, B Viana, S Tanabe, $\mathrm{Y}_{3} \mathrm{Al}_{5-\mathrm{x}} \mathrm{GaxO}_{12}: \mathrm{Cr}^{3+}$ : a novel red persistent phosphor with high brightness, Appl. Phys. Exp. 8 (2015) 042602.

[78] S K Sharma, D Gourier, E Teston, D Scherman, C Richard, B Viana, Persistent luminescence induced by near infra-red photostimulation in chromium-doped zinc gallate for in vivo optical imaging, Opt. Mater. 63 (2017) 51-58. 
[79] R Aroz, V Lennikov, R Cases, M L Sanjuán, G F de la Fuente, E Muñoz, Laser synthesis and luminescence properties of $\mathrm{SrAl}_{2} \mathrm{O}_{4}: \mathrm{Eu}^{2+}, \mathrm{Dy}^{3+}$ phosphors, J. Eur. Ceram. Soc. 32 (2012) 4363-4369.

[80] T Matsuzawa, A new long phosphorescent phosphor with high brightness, $\mathrm{SrAl}_{2} \mathrm{O}_{4}: \mathrm{Eu}^{2+}, \mathrm{Dy}^{3+}$, J. Electrochem. Soc. 143 (1996) 2670.

[81] H Terraschke, M Franzreb, C Wickleder, Magnetism and afterglow united: synthesis of novel double core-shell Eu2 +-doped bifunctional nanoparticles, Chemistry (2020).

[82] H Zhang, Z Xue, B Lei, H Dong, H Zhang, S Deng, M Zheng, Y Liu, Y Xiao, A top-down method to fabricate $\mathrm{SrAl}_{2} \mathrm{O}_{4}: \mathrm{Eu}^{2+}{ }^{2} \mathrm{Dy}^{3+}$ nanosheets from commercial blocky phosphors, Opt. Mater. 36 (2014) 1802-1807.

[83] M Nazarov, M G Brik, D Spassky, B Tsukerblat, A Nor Nazida, M N Ahmad-Fauzi, Structural and electronic properties of $\mathrm{SrAl}_{2} \mathrm{O}_{4}: \mathrm{Eu}^{2+}$ from density functional theory calculations, J. Alloys Compd. 573 (2013) 6-10.

[84] A R Schulze, $\mathrm{H}$ Ml Buschbaum, Zur Verbindungsbildung von MeO: $\mathrm{M}_{2} \mathrm{O}_{3}$. IV. Zur Struktur von monoklinem $\mathrm{SrAl}_{2} \mathrm{O}_{4}$, Z. Anorg. Allg. Chem. 475 (1981) 205-210.

[85] S A Al-Mamun, R Nakajima, T Ishigaki, Effect of liquid level and laser power on the formation of spherical alumina nanoparticles by nanosecond laser ablation of alumina target, Thin Solid Films 523 (2012) 46-51.

[86] M Abbasi, D Dorranian, Effect of laser fluence on the characteristics of Al nanoparticles produced by laser ablation in deionized water, Optic Spectrosc. 118 (2015) 472-481.

[87] C-Y Shih, R Streubel, J Heberle, A Letzel, M V Shugaev, C Wu, M Schmidt, B Gökce, S Barcikowski, L V Zhigilei, Two mechanisms of nanoparticle generation in picosecond laser ablation in liquids: the origin of the bimodal size distribution, Nanoscale 10 (2018) 6900-6910.

[88] $\mathrm{J}$ Botterman, $\mathrm{J} \mathrm{J}$ Joos, P F Smet, Trapping and detrapping in $\mathrm{SrAl}_{2} \mathrm{O}_{4}$ :Eu,Dy persistent phosphors: influence of excitation wavelength and temperature, Phys. Rev. B 90 (2014).

[89] M Nazarov, M G Brik, D Spassky, B Tsukerblat, Crystal field splitting of 5d states and luminescence mechanism in $\mathrm{SrAl}_{2} \mathrm{O}_{4}: \mathrm{Eu}^{2+}$ phosphor, J. Lumin. 182 (2017) 79-86.
[90] D Dutczak, T Justel, C Ronda, A Meijerink, $\mathrm{Eu}^{2+}$ luminescence in strontium aluminates, Phys. Chem. Chem. Phys. : Phys. Chem. Chem. Phys. 17 (2015) 15236-15249.

[91] A Bessiere, R A Benhamou, G Wallez, A Lecointre, B Viana, Site occupancy and mechanisms of thermally stimulated luminescence in $\mathrm{Ca}_{9} \mathrm{Ln}\left(\mathrm{PO}_{4}\right)_{7}(\mathrm{Ln}=$ lanthanide), Acta Mater. 60 (2012) 6641-6649.

[92] P Dorenbos, Energy of the first $4 \mathrm{f}^{7} \rightarrow 4 \mathrm{f}^{6} 5 \mathrm{~d}$ transition of $\mathrm{Eu}^{2+}$ in inorganic compounds, J. Lumin. 104 (2003) 239-260.

[93] J Bierwagen, S Yoon, N Gartmann, B Walfort, H Hagemann, Thermal and concentration dependent energy transfer of $\mathrm{Eu}^{2+}$ in $\mathrm{SrAl}_{2} \mathrm{O}_{4}$, Opt. Mater. Express 6 (2016) 793.

[94] B Cheng, H Liu, M Fang, Y Xiao, S Lei, L Zhang, Long-persistent phosphorescent $\mathrm{SrAl}_{2} \mathrm{O}_{4}: \mathrm{Eu}^{2+}, \mathrm{Dy}^{3+}$ nanotubes, Chem. Commun. (2009) 944-946.

[95] Z Fu, S Zhou, S Zhang, Study on optical properties of rare-earth ions in nanocrystalline monoclinic $\mathrm{SrAl}_{2} \mathrm{O}_{4}$ : $\mathrm{Ln}\left(\mathrm{Ln}=\mathrm{Ce}^{3+}, \mathrm{Pr}^{3+}, \mathrm{Tb}^{3+}\right)$, J. Phys. Chem. B 109 (2005) 14396-14400.

[96] Y Lin, Z Zhang, F Zhang, Z Tang, Q Chen, Preparation of the ultrafine $\mathrm{SrAl}_{2} \mathrm{O}_{4}: \mathrm{Eu}$,Dy needle-like phosphor and its optical properties, Mater. Chem. Phys. 65 (2000) 103-106.

[97] V Castaing, A D Sontakke, A J Fernández-Carrión, N Touati, L Binet, M Allix, D Gourier, B Viana, Persistent luminescence of $\mathrm{ZnGa}_{2} \mathrm{O}_{4}: \mathrm{Cr}^{3+}$ transparent glass ceramics: effects of excitation wavelength and excitation power, Eur. J. Inorg. Chem. 2017 (2017) 5114-5120.

[98] G Cristoforetti, E Pitzalis, R Spiniello, R Ishak, F Giammanco, M Muniz-Miranda, S Caporali, Physico-chemical properties of Pd nanoparticles produced by Pulsed Laser Ablation in different organic solvents, Appl. Surf. Sci. 258 (2012) 3289-3297.

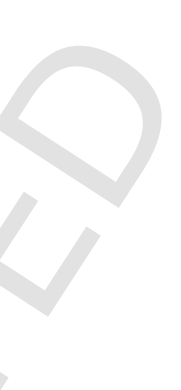

